\title{
Servindo a dois senhores: características de História e Jornalismo na produção biográfica contemporânea ${ }^{1}$ \\ Serving two masters: characteristics of History and Journalism in contemporary biographical production
}

\section{Mariana Ramalho Procopio}

Doutora e Mestre em Linguística do Texto e do Discurso pela Universidade Federal de Minas Gerais (UFMG) - Belo Horizonte (MG), Brasil. Professora Adjunta do Departamento de Comunicação Social da Universidade Federal de Viçosa (UFV) - Viçosa (MG), Brasil. E-mail: mariana.procopio@ufv.br

\section{Resumo}

Neste artigo, propomos apresentar como os campos da História e do Jornalismo se relacionam na constituição discursiva do gênero biografia. O objetivo principal foi verificar se as biografias constituídas nesses dois campos trazem marcas discursivas específicas capazes de caracterizar o gênero em cada um deles. A partir de nossas análises, foi possível perceber que alguns procedimentos biográficos - uso da ficcionalidade, apresentação das fontes, utilização de recursos iconográficos, dentre outros - tendem a se fazer presentes de modo específico nas biografias dependendo do campo de ancoragem.

Palavras-chave: biografia; Jornalismo; História.

\begin{abstract}
In this article, we propose to discuss how some aspects of History and Journalism are related in the discursive composition of the biographies. The main objective was to verify if the biographies constituted under the relations between these fields bring specific discursive marks able to characterize the genre in each of them. Through our analysis, it was possible to verify that some biographical procedures - use of fiction, presentation of sources, use of iconographic resources, among others - tends to be present in a specific way depending on the field that the biography is related.
\end{abstract}

Keywords: biography; Journalism, History. 


\section{Servindo a dois senhores: características de História e Jornalismo na produção biográfica contemporânea}

\section{Introdução}

Atualmente, as biografias constituem um importante filão do mercado editorial. Vilas Boas (2002) destaca que as biografias "Chatô - o rei do Brasil" (1994), "Mauá - empresário do império" (1995) e "Estrela Solitária: um brasileiro chamado Garrincha" (1995) estão entre os maiores sucessos de crítica e público dos anos 1990, atingindo uma média de aproximadamente 127 mil exemplares vendidos até março de 2001.

Uma observação mais atenta dessas produções biográficas nacionais revelará que, em sua grande maioria, elas são produzidas por jornalistas e em um número menor, por historiadores. Essa constatação é corroborada pelo historiador José Murilo de Carvalho, em entrevista ${ }^{1}$ concedida ao Diário do Nordeste, em 10 de agosto de 2009:

Os historiadores brasileiros não se aventuram muito a escrever biografias. Olham de uma maneira meio atravessada. Como se o gênero não estivesse à altura deles. Sempre foram os jornalistas que exploraram o gênero biográfico. E com muito sucesso. [...] Agora, os jornalistas escrevem bem, com clareza, elegância, atributos que faltam aos historiadores. Parte dos historiadores são muito rigorosos na pesquisa, mais do que os jornalistas. Principalmente, com relação às fontes. Aliás, muitos deles chegam a interpretar e criticar suas fontes de pesquisa. Não colocamos nada em nossos livros sem uma ampla pesquisa e uma documentação precisa. Quando se trabalha assim, o historiador termina por colocar uma multidão de notas de rodapés nas páginas. A leitura é muitas vezes cansativa. Atualmente, existe uma maior preocupação dos historiadores com relação à escrita, ao estilo. Isso é que atrai o leitor. (CARVALHo, 2009)

Ao pertencerem a abordagens jornalísticas ou historiográficas, acreditamos que as biografias trarão marcas de tais áreas. Assim, propusemo-nos a observar as biografias junto aos seus lugares de fala e aos seus universos de ancoragem para notar como se caracterizam tais narrativas a partir de seu campo temático.

A fim de que possamos caracterizar História e Jornalismo, retomamos a noção de campo, desenvolvida pelo sociólogo Pierre Bourdieu (1989). De acordo com ele, os atores

1 Disponível em http://diariodonordeste.globo.com/materia.asp?codigo=660548. Acessado em 20 de março de 2011. sociais se encontram inseridos em um determinado contexto social que, de certo modo, interfere em seu comportamento por estarem expostos às influências culturais, sociais, econômicas, políticas, artísticas etc. Em razão das influências variadas, é possível notar certa disputa entre os grupos e os valores por eles defendidos. O campo social surge, então, como local no qual se configuram as disputas, cada grupo tentando legitimar seus próprios valores.

A partir dessa conceituação, trataremos História e Jornalismo (entendido aqui como pertencente à esfera da mídia e da comunicação social) como campos discursivos, locais nos quais interagem as diversas vozes, as diversas fontes enunciativas de um mesmo domínio ou tema. Ainda que existam posicionamentos contrários e divergentes no interior de tais campos, tentaremos construir uma identidade a partir de um posicionamento específico em cada campo: o da Nouvelle Histoire, no caso da História, e o do "Jornalismo Literário", no caso do Jornalismo.

\section{O campo da História: definições, posicionamento da Nova História e a biografia nesse universo}

No senso comum, é possível dizer que a História consiste na ciência que estuda o homem e sua ação no tempo e no espaço, por meio da investigação do passado, do presente e de sua interferência no futuro. Menezes (2004, p. 38) complementa:

Nascida no século XIX sob a égide do positivismo, a ciência histórica constituiu-se em torno do registro dos acontecimentos do passado. Essa era a sua particularidade, em relação aos outros campos. A observação dos acontecimentos distantes do tempo vivido pelo historiador (como garantia de neutralidade) levaria à descoberta de regularidades e à formação de leis (a exemplo das ciências experimentais) de evolução da vida social.

Desde a Antiguidade, a História tem sido escrita sob a forma de narrativa, notadamente sobre os grandes feitos dos grandes homens, os acontecimentos políticos e conquistas militares. Tais acontecimentos eram visualizados em uma relação de causa e consequência, capaz de permitir uma reconstituição linear e objetiva do passado e da trajetória humana.

O discurso historiográfico apresenta estatuto factual, no qual o historiador faz uso de procedimentos e abordagens capazes de conferir ao seu discurso um valor de verdade, além 
de se tornar passível de credibilidade. A fim de construir esse discurso de verdade, o ofício historiográfico apresenta algumas regras, dentre as quais Del Priore (2009) destaca:

- a pesquisa documental;

- a crítica interna e externa da documentação;

- a interpretação das informações trazidas pelas fontes;

- o diálogo com os especialistas do assunto, a fim de elucidar pontos obscuros;

- a inclusão de notas e referências sobre as informações coletadas e as fontes consultadas;

- o preenchimento das lacunas por meio da mediação do historiador.

É possível dizer que os eventos concretizados na narrativa são sempre apreendidos de maneira indireta e incompleta, ou seja, compreendidos somente por meio de alguns indícios. Assim, cabe ao historiador investigar tais indícios e completar as lacunas a fim de conferir aos eventos uma relação, um sentido. A descrição é seletiva, fazendo com que um fato se constitua em um "cruzamento de itinerários possíveis" e não em uma unidade natural. A construção do sentido depende, pois, das fontes e documentos, mas, sobretudo, do historiador.

Contudo, mais do que apenas narrar, a História deve explicar, e essa explicação não é mais do que a maneira como a narração se organiza em uma trama compreensível. Assim, a explicação histórica é o que Veyne (1971) chama de compreensão - o resultado de uma narração suficientemente documentada. Em síntese, é preciso dizer que a História não deve ser compreendida como uma simples sucessão de fatos interligados, mas sim que ela é uma disciplina em permanente construção e, por estar nesse processo contínuo, não admite uma definição única. Toda narrativa histórica é uma construção e nós somos os sujeitos que a constroem, o que faz com que todo conhecimento histórico esteja sendo sempre revisto.

Durante muito tempo, biografia e História não tiveram uma relação amistosa, principalmente pela recusa da narrativa pelos historiadores, considerada inadequada para a escrita histórica. A recusa da historiografia em trabalhar com a biografia deveu-se também ao fato de esta última poder perturbar os objetivos de cientificidade característicos do campo historiográfico.
Loriga (2010) acentua que à biografia sempre esteve reservado um papel secundário. A História busca redescobrir o passado, o coletivo, enquanto a biografia poderia dar conta apenas dos indivíduos e da parcialidade por eles vivenciada. Malatian (2008) complementa que a separação entre a biografia e a História se estabelece não só nessa ancoragem na narrativa mas, sobretudo, no fato de a primeira tradicionalmente se reservar ao estudo dos fatos e gestos dos indivíduos, enquanto a segunda se dedica ao relato dos acontecimentos coletivos.

Contudo, é a partir de década de 1980 que a biografia conquista seu lugar na historiografia. Essa conquista deveu-se principalmente à crise do paradigma estruturalista, o que implica uma recuperação do lugar do sujeito na História. Além disso, a aproximação das tendências historiográficas com a Antropologia e com a própria Literatura contribuiu para a biografia figurar como objeto de interesse da História. Nesse sentido, Del Priore (2009, p. 9) explica:

A reabilitação da biografia histórica integrou as aquisições da história social e cultural, oferecendo aos diferentes atores históricos uma importância diferenciada, distinta, individual. Mas não se tratava mais de fazer, simplesmente, a história dos grandes nomes, em formato hagiográfico - quase uma vida de santo sem problemas, nem máculas. Mas de examinar os atores (ou o ator) célebres ou não, como testemunhas, como reflexos, como reveladores de uma época. A biografia não era mais a de um indivíduo isolado, mas, a história de uma época vista através de um indivíduo ou de um grupo de indivíduos. Ele ou eles não eram mais apresentados como heróis, na encruzilhada de fatos, mas como uma espécie de receptáculo de correntes de pensamento e de movimentos que a narrativa de suas vidas torna mais palpáveis, deixando mais tangível a significação histórica geral de uma vida individual.

A "virada" epistemológica evidenciada nas biografias foi promovida pela Nouvelle Histoire francesa e na micro-história italiana na década de 1980. As duas abordagens diminuem o foco da História, concentrando-se no tempo significativo de fatos, ações e representações que cercam o indivíduo. Suas temáticas estão ligadas ao cotidiano de comunidades, às situações-limite e às biografias ligadas à reconstituição de microcontextos ou dedicadas a personagens extremos, geralmente figuras anônimas, que passariam despercebidas na multidão. Nesse sentido, a proposta é realizar não uma história de generalidades, mas uma história que privilegie a singularidade. 


\section{Servindo a dois senhores: características de História e Jornalismo na produção biográfica contemporânea}

Levi (1989) acrescenta que a biografia, renovada nos moldes da Nova História, não deve mais ser entendida como uma narrativa tradicional de uma personalidade coerente e estável. Le Goff (2005) acrescenta que a nova biografia busca estudar seus personagens em sua complexidade por meio de suas múltiplas funções e papéis.

\section{O campo do Jornalismo: definições, o posicionamento do Jornalismo Literário e a biografia nesse contexto}

Albert e Terrou (1990) afirmam que o desenvolvimento da atividade jornalística está relacionado a uma "necessidade orgânica" da sociedade, uma vez que a necessidade de informação é um dos dados fundamentais da toda a vida social. O Jornalismo caracteriza-se pelo relato dos fatos que têm repercussão pública. A fim de garantir um relato completo, o jornalista busca a identificação das pessoas que participaram dos acontecimentos, a localização das ações sobre as quais o relato se debruça e a circunscrição temporal do momento das ocorrências.

No que diz respeito às suas finalidades, Charaudeau (2006) relata que o discurso midiático, no qual está contido o Jornalismo, apresenta uma dupla finalidade: o "fazersaber", configurando assim uma visada de informação; e o "fazer-sentir", instaurando a visada de captação. Com o intuito de satisfazer plenamente às duas visadas, o jornalista encontra-se submetido a uma empreitada que pode se apresentar como paradoxal: ao mesmo tempo em que ele deve relatar fielmente o acontecimento, primando por uma objetividade, o seu relato não pode prescindir da visada de captação.

A fim de determinar os tipos de fatos passíveis de se transformarem em acontecimentos midiáticos/jornalísticos, são estabelecidos os critérios de noticiabilidade. ${ }^{2}$ De acordo com Wolf (1999), a noticibilidade corresponde ao conjunto de critérios, operações e instrumentos por meio dos quais os meios de comunicação selecionam, cotidianamente, os fatos que devem se tornar notícias. Entre os principais critérios de noticiabilidade, destacam-se: proximidade, atualidade, identificação social, intensidade, ineditismo e identificação humana.

Em suma, é possível dizer que a atividade jornalística sempre esteve ancorada na função de representação e relato fiel dos fatos acontecidos na sociedade. Por esse atributo,

2 Os critérios de noticiabilidade também podem ser chamados de valores-notícia. todo e qualquer gênero jornalístico - nota, notícia, reportagem, editorial, etc. - é considerado como pertencente ao estatuto factual, uma vez que a ancoragem na realidade já faz parte de sua constituição.

Para captar o universo ao qual se propõem a relatar, alguns jornalistas praticam uma inserção profunda na realidade que desejam captar, caracterizando, assim, a modalidade conhecida como Jornalismo Literário. Um dos objetivos dessa modalidade é aprofundar o conhecimento dos fatos pela representação da experiência vivida e observada, a partir de uma preocupação estética, que fará uso de procedimentos costumeiramente ligados ao universo literário. O Jornalismo Literário caracteriza-se, assim, por uma renovação estilística, ideológica e funcional.

Na ótica do Jornalismo Literário, a imersão no universo do personagem, bem como o uso da subjetividade para a captação e construção da narrativa, deverá funcionar como ferramenta a fim de tornar a reportagem mais humanizada, diferente do que acontece nas coberturas jornalísticas cotidianas. Sims (1999) acredita que a adoção de tais preceitos contribui também para demonstrar audácia, autoridade, credibilidade e emoção do jornalista e de seu relato.

Essa alteração no modo de se captar a realidade e de transmiti-la nos textos jornalísticos acarreta também uma mudança no que se refere à própria escrita da reportagem. A esse novo expoente da escrita jornalística, o Jornalismo Literário, está indicado um texto informativo de maior acuidade, com maior preocupação com os detalhes e com tendência a mais emprego de recursos literários. Percebe-se, pois, que o Jornalismo Literário permite a seus praticantes uma liberdade maior não só quanto à escolha da temática tratada, da angulação e dos procedimentos de apuração e investigação jornalística, mas também dos recursos discursivos e estilísticos da apresentação da reportagem. Entre os principais procedimentos adotados e capazes de caracterizar o jornalismo literário, Wolfe (2005) destaca:

- Construção cena a cena da história, isto é, um relato exaustivo dos fatos na medida em que eles que vão acontecendo, destacando também seus desdobramentos.

- Registro completo dos diálogos.

- Apresentação de cada cena por pontos de vista variados, pelos diversos envolvidos.

- Registro de hábitos, costumes, roupas, gestos e outros detalhes representativos. 
Ainda no intuito de caracterizar os procedimentos adotados pelos jornalistas que praticam a abordagem literária, Lima (2004) acrescenta nesse rol:

- Construção de um sumário ou exposição, que seria uma espécie de resumo de uma ação secundária, contextualizando a ação principal, eixo da narrativa.

- Cena presentificada da ação, que seria uma construção detalhada do desenvolvimento das ações.

- Apresentação de pontos de vista variados, do jornalista, do personagem e de demais envolvidos na narrativa.

- Utilização de metáfora e figuras da retórica.

- Presença de citações diretas, como elemento de construção da credibilidade da narrativa.

- Preocupação com a apresentação de fontes, dados e documentação, também como estratégia de credibilidade.

Entre os principais gêneros utilizados pelo Jornalismo Literário, podemos destacar o livro-reportagem. Como alternativa para fugir das amarras da padronização jornalística e com isso garantir um relato mais profundo e criativo de assuntos variados:

[...] o livro-reportagem é o veículo de comunicação impressa não-periódico que apresenta reportagens em grau de amplitude superior ao tratamento costumeiro nos meios de comunicação jornalística periódicos. Esse "grau de amplitude superior" pode ser entendido no sentido de maior ênfase de tratamento ao tema focalizado - quando comparado ao jornal, à revista ou aos meios eletrônicos - , quer no aspecto extensivo, de horizontalização do relato, quer no aspecto intensivo, de aprofundamento, seja quanto à combinação desses dois fatores. (LIMA, 2004, p. 26)

Por meio de suas características principais, como a falta de periodicidade e a liberdade em relação ao factual, os jornalistas encontram no livro-reportagem um local apropriado para tratarem, com liberdade de tema e de escrita, assuntos que consideram importantes de serem levados ao público, com as devidas reflexões feitas. No universo jornalístico, a biografia é identificada por Lima (2004) como uma das modalidades de livro-reportagem, destacando-a como uma das recorrências mais presentes no cenário editorial nacional.

O jornalismo biográfico insere-se nas modalidades não periódicas de retratação dos fatos, isto é, trata-se de um texto com características jornalísticas, mas que não obedece aos preceitos de periodicidade dos gêneros jornalísticos, pois faz uso de outro suporte: o livro. A atividade biográfica permite aos jornalistas a realização de um trabalho narrativo de fôlego, no qual o jornalista-biógrafo se depara com a possibilidade de emprego de recursos narrativos diferenciados daqueles costumeiramente utilizados nas rotinas de produção das redações. Nesse âmbito, a biografia consiste na narração da vida de uma pessoa a partir do plano de leitura adotado pelo autor que, no caso dessa abordagem, é um jornalista.

\section{Características historiográficas e jornalísticas na estruturação discursiva das biografias: algumas considerações}

Para que pudéssemos apontar características dos campos abordados anteriormente, propusemos uma reflexão acerca do gênero biografia em uma abordagem discursiva. Vislumbrou-se relacionar as biografias aos seus lugares de fala, aos seus universos de ancoragem, a fim de caracterizar discursivamente o gênero e o próprio "fazer biográfico" no cenário nacional. Inicialmente, procedemos à leitura de algumas biografias contemporâneas, escritas tanto por historiadores quanto por jornalistas, que nos permitissem observar essas ocorrências. ${ }^{3}$ Uma vez que não é nosso objetivo proceder a uma análise de uma ou várias biografias específicas, preferimos não nos ater a uma análise exaustiva de um ou outro exemplar, mas observar um universo maior que nos permitisse chegar às considerações sobre as quais passaremos a discorrer. A nosso ver, o importante é dizer aqui o que temos observado no tocante às características de História e Jornalismo em narrativas biográficas variadas.

Contudo, como o volume de títulos encontrados para leitura e observação foi grande, vimo-nos obrigados a redefinir os

3 Faz-se necessário dizer que procedimento metodológico semeIhante foi por nós adotado na elaboração de nossa tese de doutorado "A configuração discursiva de biografias a partir de algumas balizas de História e Jornalismo," defendida em dezembro de 2012, no Programa de Pós-Graduação em Estudos Linguísticos da Universidade Federal de Minas Gerais. Uma vez que nossa tese configurou-se mais como reflexão teórica do gênero biografia, optamos por inicialmente realizar uma leitura flutuante de biografias variadas. Coletamos o máximo de biografias possíveis e procedemos à leitura delas. Em seguida, estabelecemos categorias de análise e levantamos os dados que nos eram necessário, bem como exemplos e excertos ilustrativos das narrativas variadas. 


\section{Servindo a dois senhores: características de História e Jornalismo na produção biográfica contemporânea}

procedimentos metodológicos da pesquisa. Verificamos a necessidade de selecionar algumas narrativas, a fim de que fosse possível constatar empiricamente como as especificidades do fazer biográfico se apresentam. Preferimos não adotar a nomenclatura corpus; optamos por dizer que selecionaríamos algumas narrativas para exemplificar as reflexões empreendidas. Após um levantamento exaustivo de dados, decidimos fixar como recorte temporal para nossa pesquisa o período de 1981 a 2010, o que corresponderia a 30 anos de biografismo nacional. Em seguida, partimos das considerações de Galvão (2005) sobre o ranking dos personagens biografados no Brasil. Segundo a autora, os personagens mais biografados fazem referência aos seguintes universos: (i) Música; (ii) Política; (iii) jornalistas e personalidades dos meios de comunicação.

No entanto, ainda que essa classificação se mostrasse como um bom parâmetro para nosso recorte, acreditávamos ser mais interessante selecionar biografias cujos temas ou ocupações dos personagens fossem encontrados na História e no Jornalismo. Observamos, pois, quais eram as ocupações ou características de personagens biografados nesse período que tinham sido biografados tanto por historiadores quanto por jornalistas. A partir daí, encontramos informações que nos permitiram estabelecer três categorias de personagens biografados: "Personalidade Política"; "Personalidade Artística" e "Personalidade Empresarial." São elas:

(1) Categoria Política - "Condessa de Barral: a paixão do imperador" (2008), autoria da historiadora Mary Del Priore; "Olga" (1985) escrita pelo jornalista Fernando de Morais.

(2) Categoria Personalidade Artística - "Joaquim Callado: o pai do choro" (2008), escrita pelo historiador André Diniz; "Carmen: uma biografia" (2005), obra do jornalista Ruy Castro.

(3) Categoria Personalidade Empresarial - "Joaquim da Silva: um empresário ilustrado do império” (2007), escrita pelo historiador Francisco Salles Gaudêncio; "Mauá: o empresário do império" (1995), do jornalista Jorge Caldeira.

De modo geral, a biografia constitui-se como um gênero de estatuto factual, que tem como objetivo informar, relatar a vida de um personagem para leitores que nele tem interesse ou ainda revelar a vida de um personagem desconhecido pela sociedade. Por ser um gênero de estatuto factual, percebe-se um comprometimento com a referencialidade do universo narrado. Nesse aspecto, é possível encontrarmos uma série de procedimentos discursivos reveladores de um fazer estratégico, que visa à conquista da legitimidade e da credibilidade da biografia. Documentos, fotografias, citações de especialistas e depoimentos de fontes próximas ao personagem são utilizados como provas de verdade, implicando a construção de efeitos de real na narrativa biográfica.

Todavia, percebe-se na estrutura narrativa das biografias o recurso da ficcionalidade, principalmente para ilustrar situações narradas pelo biógrafo e para auxiliar na construção de uma estratégia de captação. Recriações de conversas e recursos como flashbacks são representativos desse fazer estratégico. Ainda no que diz respeito à estratégia de captação, pudemos verificar a mobilização constante de descrições subjetivas e minuciosas, com fins de provocar efeitos patêmicos. Geralmente, as vidas reveladas são escolhidas em razão de terem episódios classificados pelos biógrafos como especiais, excêntricos e diferenciados, o que já indica a vinculação a um universo patêmico intenso. A organização narrativa, isto é, a construção das relações entre ações e personagens envolvidos na trama narrada, evidencia com detalhes os pontos altos dessas histórias, os momentos de clímax e de desfechos das intrigas narradas. Toda essa narração é capaz de despertar disposições afetivas nos sujeitos destinatários dessa mensagem.

No que se refere à literalidade das biografias, pensamos que tanto jornalistas como historiadores fazem usos de procedimentos discursivos que contribuem para essa característica. Recursos como diálogos, monólogos interiores e fluxos de consciência foram incorporados para cativar os leitores, buscando conquistar sua atenção de forma mais agradável e leve. $\mathrm{O}$ aspecto imensamente descritivo também pode indicar uma estratégia de captação, convidando os leitores a conhecerem de maneira mais completa o universo do personagem retratado.

No que diz respeito ao uso da ficcionalidade, este se encontra permitido no trabalho histórico-biográfico, sobretudo para preencher lacunas no processo investigativo. No entanto, as passagens ficcionais ou aquelas cuja verificação não foi totalmente possível devem estar claramente identificadas, a fim de que seja possível discernir entre o que foi devidamente apurado e comprovado e aquilo que foi "criado" pelo historiador.

Em relação ao trabalho biográfico-jornalístico a interface com a Literatura parece saltar aos olhos. A adoção de procedimentos narrativos costumeiramente identificados como literários, bem como o uso de artifícios estilísticos mais elaborados aos padrões da escrita jornalística cotidiana, constituem-se como elementos importantes na identificação da biografia jornalística. Entre os principais procedimentos adotados, destacamos aqueles já identificados e 


\section{Servindo a dois senhores: características de História e Jornalismo na produção biográfica contemporânea}

identificadores do jornalismo biográfico, como: construção cena a cena da história; registro completo dos diálogos; apresentação de cada cena pelo ponto de vista de personagens variados; preocupação com o conteúdo descritivo, sobretudo de hábitos, costumes, roupas, gestos e outros detalhes representativos; uso de metáforas e figuras de linguagem.

Nos dois campos, por mais fiel que seja aos preceitos de objetividade, de investigação científica, o biógrafo sempre se verá diante de informações subjetivas e fará uso de sua subjetividade para selecionar as informações acerca da vida do outro. O modo pelo qual o biógrafo irá lidar com essa subjetividade tende a ser influenciado pelo campo de referência das biografias e dos biógrafos. Parece-nos que os biógrafos historiadores têm uma preocupação maior em deixar claro, no interior da narrativa, as passagens que são fruto da reconstrução do biógrafo ou que ainda estão sob suspeição. Por meio da modalização, eles indicam que determinadas informações não são totalmente comprovadas. Esse procedimento não costuma ser verificado no caso da biografia escrita por jornalistas. Somos levados a crer que, no caso da narrativa em si, a preocupação maior seja a fluidez textual. No entanto, os biógrafos jornalistas parecem fazer uso melhor das seções paratextuais - apresentação, dedicatória, agradecimentos, etc. - para apresentar informações quanto à procedência das informações e sobre o "fazer-biográfico".

O "fazer-biográfico" tende a ser mais retratado pelos jornalistas do que pelos historiadores. A nosso ver, o biógrafo-historiador tem seu trabalho espelhado no ofício do próprio historiador e, por já estar, de certa maneira, cristalizado, não há necessidade de sua explicação. No caso dos biógrafos-jornalistas, o trabalho se diferencia da atividade do jornalista-padrão em virtude, principalmente, do tempo maior de investigação, da possibilidade de recursos de escrita diferenciados, da extensão maior do relato, etc. Assim, o biógrafo-jornalista deve explicar o seu próprio trabalho, demonstrando que ele se difere e se aprofunda em relação ao jornalismo convencional.

Em relação a algumas particularidades do discurso biográfico no âmbito historiográfico, podemos ainda comentar sobre as fontes. De acordo com Le Goff (2005), as fontes constituem uma multiplicidade de documentos: escritos ou orais, produtos de escavações arqueológicas, fotografias, filmes, publicidades, etc. Mais importante do que as fontes, entretanto, é o olhar crítico que a elas se deve destinar: quem produziu determinado vestígio? Em que situação? Com quais interesses? A credibilidade das fontes está atrelada justamente à suspeição delas. Nenhuma fonte está livre de isenção, já que ela é produto intencional de uma sociedade. O biógrafo-historiador procura detalhar as fontes com uma maior riqueza de detalhes por contextualizar de maneira explícita e metódica de onde tais informações foram retiradas.

Já no campo do Jornalismo, a apresentação das fontes nem sempre está muito clara. Os jornalistas costumam apresentá-las no final da obra, em seção específica e geralmente desconectadas de sua aparição na narrativa. Nesse sentido, no caso do biógrafo-jornalista, a preocupação maior parece ser com a fluidez do texto. Ainda que o autor apresente as falas e depoimentos marcadamente diferentes dos seus, a identificação separada das fontes não favorece a verificação da procedência delas.

Em relação aos personagens mais costumeiramente biografados pela História, podemos citar personalidades históricas e pessoas anônimas. No caso das personalidades históricas, percebe-se tanto um resgate de pessoas importantes e ilustres quanto de indivíduos negligenciados pela sociedade, mas que se destacaram em algum aspecto da vida econômica, cultural e social. Outra parcela costumeiramente biografada pela vertente historiográfica são as pessoas subalternas, comuns, sobre as quais se pretende resgatar, a partir da vida desses indivíduos, novos olhares sobre a história. Ao biografar personagens esquecidos pela História oficial, o historiador consegue identificar costumes, valores e representações dos grupos ao qual o biografado está associado.

Os jornalistas, por outro lado, tendem a biografar celebridades ou personalidades relativamente contemporâneas. Algumas vezes, a escolha do personagem biografado está condicionada à exigência do mercado editorial, que prefere escolher personagens já conhecidos do público e que nele despertariam curiosidade. Ruy Castro, em conferência proferida no Fórum das Letras de Ouro Preto, em 2009, ${ }^{4}$ ressaltou por diversas vezes que, antes de escrever a biografia de Carmen Miranda, já era fascinado pela cantora. Essa admiração foi um alicerce fundamental para que o autor dedicasse cerca de cinco anos no processo de investigação e escrita da narrativa. Durante esse tempo, Ruy teve um grave problema de saúde - um câncer de garganta mas não se afastou do trabalho. Vilas Boas (2002) também

4 Conferência "Perfis Biográficos: entre a realidade e o mito", proferida por Humberto Werneck, Paulo Markun e Ruy Castro, no dia 31 de outubro de 2009, como parte das atividades desenvolvidas no quinto Fórum das Letras da Universidade Federal de Ouro Preto, realizado entre os dias 29 de outubro e 02 de novembro de 2009. 


\section{Servindo a dois senhores: características de História e Jornalismo na produção biográfica contemporânea}

chama atenção para essa relação de respeito e admiração que deve existir entre biógrafo e biografado. O personagem escolhido para ter a vida contada pode ser bandido ou herói, mas deve estimular a capacidade criativa e investigativa do jornalista-biógrafo.

O uso de recursos icônicos é presente nas biografias dos dois campos. Entretanto, ainda podemos dizer que o uso de recursos variados ainda é mais presente nas biografias escritas por jornalistas, talvez pelo fato de estes já estarem habituados ao uso de elementos diferenciados na construção de narrativas jornalísticas.

Além disso, as biografias históricas têm como modelo convencional os padrões acadêmicos, privilegiando uma configuração mais erudita e científica. De uma maneira geral, é possível dizer que a maioria das biografias produzidas no âmbito da História quase sempre esteve ancorada em um paradigma acadêmico. Procurava-se, por meio das obras, documentar uma época a partir da história de um indivíduo. A biografia se configurava como local de reconstituição da memória coletiva e individual, constituindo obras de caráter documental, geralmente direcionadas a um público especializado.

Entretanto, é possível notar que esse modelo tradicional da biografia histórica parece estar sendo readaptado pelos biógrafos-historiadores por meio da adoção maior de recursos literários, do uso de recursos iconográficos, de uma escrita mais leve e de uma diagramação diferenciada. Essas transformações podem indicar uma necessidade de readaptação da biografia histórica frente à explosão e ao sucesso editorial das biografias escritas por jornalistas. Nesse aspecto, Del Priore (2009, p. 14) comenta:

[...] historiadores brasileiros terão que repensar que tipos de texto produzirão e entre eles, qual seria o papel da biografia histórica, tão eficiente para dar a conhecer o passado. Agora, não mais para atender exclusivamente às exigências herméticas da Academia, mas, também para responder a uma exigência ou demanda social. Há milhares de leitores para um tal produto cultural. Não há nada de anedótico nesta iniciativa, se ela for realizada no cumprimento das exigências da profissão. Se ninguém contesta o talento de tantos romancistas e jornalistas que se aventuraram a escrever biografias históricas, por que recusar a pertença ao domínio literário aos biógrafos que são historiadores de formação?

Por meio dessas observações, somos levados a dizer que os biógrafos vêm rompendo, de um lado, com o jornalismo cotidiano (amarrado a técnicas como o lead), por meio da exploração dos recursos da literatura, e, de outro lado, formando um novo modo de narrar vidas que até recentemente vinha sendo desenvolvido por outros profissionais como os cultores da Nova História. Esse modo romanceado de narrar constrói um texto aprofundado e agradável que consegue transmitir de maneira significativa a história de pessoas de relevância para a compreensão da contemporaneidade.

A preocupação central dos biógrafos, tanto jornalistas como historiadores, parece ser a revelação dos múltiplos fios que ligam um indivíduo ao seu contexto. Os biógrafos tendem a abandonar a apresentação "mecânica" e sistemática das histórias de vida, atribuindo a elas uma conotação mais humanizada, com a ancoragem no contexto histórico e social.

\section{Considerações finais}

Não consideramos que as especificidades e diferenças acima apontadas sejam suficientes para demarcarmos fronteiras estanques entre biografias escritas por historiadores e jornalistas. Ainda, em um mesmo campo de ancoragem, é possível perceber comportamentos e características de campos variados, como literário, jornalístico, historiográfico, sociológico e outros.

O que foi possível perceber é que as biografias tendem a obedecer a uma série de restrições, situacionais e discursivas, independentemente desse campo de ancoragem. As estratégias discursivas empreendidas são aplicadas mais para garantir a credibilidade da narrativa e a captação de possíveis leitores do que para a especificação do campo das narrativas.

Ademais, as biografias consideradas sob o ponto de vista do discurso constituem-se como práticas sociais por excelência e, assim, não poderiam ser estudadas fora de uma esfera situacional, a qual motivaria e ofereceria as condições de emergência desse enunciado social. Nas palavras de Maingueneau (2001, p. 30):

A obra só se constitui implicando os ritos, as normas, as relações de força das instituições literárias. Ela só pode dizer algo do mundo inscrevendo o funcionamento do lugar que a tornou possível, colocando em jogo, em sua enunciação, os problemas colocados pela inscrição social de sua própria enunciação. 


\section{Referências}

Albert, Pierre \& Terrou, Fernand. História da imprensa. São Paulo: Editora Martins Fontes, 1990.

Bourdieu, Pierre. O poder simbólico. Rio de Janeiro: Bertrand Brasil, 1989.

Carvalho, JoséMurilo.ParadoxosdaDemocracia.Entrevista publicada no Caderno 3 do Diário do Nordeste, em 10 de agosto de 2009. Disponível em: <http://diariodonordeste. globo.com $/$ materia.asp?codigo $=660548>$. Acesso em: 20 mar. 2011.

Charaudeau, Patrick. Discurso das Mídias. São Paulo: Contexto, 2006.

Del Priore, Mary. Biografia: quando o indivíduo encontra a história. Topoi, Rio de Janeiro, v. 10, n. 19, jul-dez. 2009, p. 7-16.

Galvão, Walnice Nogueira. A voga do biografismo nativo. In: Estudos Avançados. vol.19. n.55. São Paulo Set./Dez. 2005. p. 350-366. Disponível em http://www.scielo.br/ scielo.php?pid=S0103-40142005000300026\&script $=$ sci arttext Acesso em 02/08/2011.

Le Goff, Jacques. A História nova. In: Le Goff, Jacques; Chartier, Roger; Revel, Jacques. (orgs) A História nova. 5 ed. São Paulo: Martins Fontes, 2005. p. 31-84.

LeVI, Giovanni. Les usages de la biographie. In: Annales. Économies, Sociétés, Civilisations. 44e année, n. 6, 1989, pp. 1325-1336. Disponível em <http://www.persee.fr/web/ revues/home/prescript/article/ahess_03952649_1989_ num_44_6_283658>. Acesso em: 10 jan. 2011.
LıMA, Edvaldo Pereira. Páginas ampliadas: O livroreportagem como extensão do jornalismo e da literatura. São Paulo: Manole, 2004.

LoRIGA, Sabina. Le petit X - De La biographie á l'histoire. Paris: Seuil, 2010.

Maingueneau, Dominique. O contexto da obra literária: enunciação, escritor e sociedade. 2 ed. São Paulo: Martins Fontes, 2001.

Malatian, Teresa Maria. A biografia e a história. Cadernos CEDEM. São Paulo. 2008, v. 1, p. 16-31. Disponível em: <http://www.cedem.unesp.br/cadernoscedem.pdf >. Acesso em: 30 abr. 2011.

Menezes, William Augusto. Evento, jogo e virtude nas eleições para a presidência do Brasil - 1994 e 1998. Tese de Doutorado em Estudos Linguísticos. Belo Horizonte, Faculdade de Letras, Universidade Federal de Minas Gerais, 2004.

SIms, Norm. Literary Journalism. USA: Ballantine Books, 1999.

VeYne, Paul. Comment on écrit l'histoire - Essay d'epistémologie. Paris: Seuil, 1971.

VILAS BOAS, Sergio. Biografias e biógrafos: jornalismo sobre personagens. São Paulo: Summus, 2002.

Wolf, Mauro. Teorias da Comunicação. 5 ed. Lisboa: Presença, 1999.

WolfE, Tom. Radical chique e o novo jornalismo. 2 ed. São Paulo: Companhia das Letras, 2005. 